\title{
Un peptide de synthèse inhibe les métastases du mélanome de souris
}

Une nouvelle parue dans $\mathrm{m} / \mathrm{s}$ en juin 1986 (p. 337) signalait l'importance de la séquence d'acides aminés RGD dans la reconnaissance entre des protéines, en particulier la fibronectine et la surface des cellules. Un peptide soluble contenant RGD empêche la liaison de la fibronectine aux cellules. Cette découverte est susceptible de nombreuses applications dans tous les domaines de la biologie et de la médecine. Humphries et al. (Bethesda) viennent d'en fournir une illustration frappante [1]. L'injection de cel- lules du mélanome murin B16-F10 entraîne chez la souris $\mathrm{C}_{57} \mathrm{BL} / 6$ l'apparition en deux semaines de colonies mélanotiques dans les poumons. Si l'on injecte en même temps le pentapeptide GRGDS (Gly-Arg-Gly-Asp-Ser), on diminue de 75 à $95 \%$ le nombre de colonies; des peptides différents ou même très peu modifiés n'ont aucun effet. Le mécanisme d'action consiste en une inhibition de la fixation des cellules de mélanome sur le tissu pulmonaire et une accélération de leur déplacement.
Le peptide n'est pas toxique pour la souris. On peut donc envisager un traitement rationnel de maladies qui comportent des processus d'invasion ou d'adhésion excessives, et notamment la prévention de certaines métastases cancéreuses après ablation de la tumeur primitive.

J.-C. D.

1. Humphries MJ, Olden $\mathrm{K}$, Yamada KM. A synthetic peptide from fibronectin inhibits experimental metastasis of murine melanoma cells. Science $1986 ; 233: 467-70$.

\section{Localisation précise du gène de l'hémochromatose héréditaire}

$L$ 'article de Brissot et al. (ce numéro, p. 542) souligne l'importance de la liaison génétique entre le gène de l'hémochromatose héréditaire et le système HLA. Edwards et al. (Salt Lake City) viennent [1] d'apporter une précision capitale à la localisation de ce gène, grâce à l'étude d'une famille comportant trois enfants atteints. Le Tableau montre les formules $H L A$ de cette famille, les germains 1, 2 et 3 étant hémochromatosiques et les parents étant hétérozygotes.

$L$ 'examen des deux premiers enfants montre que les allèles liés à la transmission de la tare sont $A_{2} B_{13}$ chez le père et $A_{29} B_{44}$ chez la mère. Chez le troisième enfant, la transmission maternelle est liée seulement $\dot{a} B_{44}$ et donc ségrège avec l'antigène $H L A B$, l'haplotype $A_{2} B_{44}$ résultant d'une recombinaison chez la mère. D'après les auteurs, il s'agit là du premier exemple décrit de recombinaison chez un sujet porteur d'une hémochromatose liée au système HLA dont l'allèle hémochromatosique ségrège avec l'antigène $H L A-B$ et non avec $H L A-A$. Ils en concluent que le locus de l'hémochromatose doit se trouver entre ceux de $H L A-A$ et de HLA-B, et non à l'extérieur de la région $H L A$.

J.-C. D.

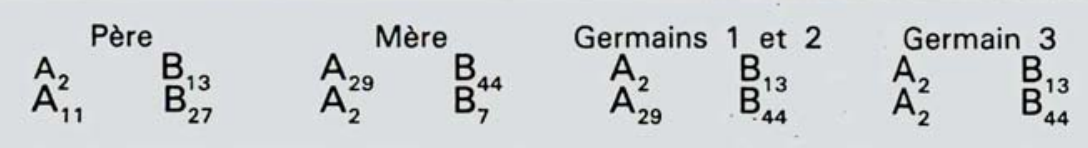

1. Edwards CQ Griffen LM, Dadone MM, Skolnick MH, Kushner JP. Mapping the locus for hereditary hemochromatosis : localization between HLA-B and HLA-A. Am J Hum Genet 1986 ; 38 : 805-11. 